\title{
SETI FROM THE MOON: AVOIDING RADIO POLLUTION FOR FUTURE RADIO- ASTRONOMY
}

\author{
J. HEIDMANN \\ Paris Observatory \\ (heidmann@obspm.fr; FAX: 33-145077939)
}

\begin{abstract}
Because of the ever increasing human-made radio frequency interference (RFI), we propose to IAU a Resolution for protecting the well singled out lunar farside $100 \mathrm{~km}$ diameter SAHA crater from any future RFI for the scientific benefit of the coming decades high-sensitivity radioastronomy at large. Immediate and pragmatic action is strongly recommended. Our strategy, different from the ones of a recent ITU Recommendation, could increase our bargaining possibilities.
\end{abstract}

\section{Background}

I developed arguments showing that it is not unreasonable to conjecture that within the next 2 or 3 decades humankind may be deeply involved in collecting information contained in signals emitted from many different extraterrestrial technologies (Heidmann 1996). Unfortunately, the sensitivity progress of our radioastronomical technology are being increasingly drowned by the tremendous development of human-made radio interference (RFI), arising mainly from satellite radio beams illuminating from above our ground-based radiotelescopes (McNally 1992; Gérard 1993, 1996; Whiteoak 1992, 1997; Roth 1997).

This is why a few years ago I started to define a well specified lunar farside radio observatory potential site (the $100 \mathrm{~km}$ diameter crater SAHA) and called for immediate action in order to have its now pristine environment protected from any RFI for future scientific research. A typical example of catastrophic RFI would be provided by a telecommunication radio satellite positioned at a lagrangean point in view on the Moon farside. It is evident from the disasterous experience of radioastronomers with FRI on Earth, that immediate action is strongly recommended. I already initiated it within various learned bodies, such as IAA, IISL, COSPAR, ILEWG (Heidmann 1997b).

Of course the requirements I presented from SETI work are readily extendable to the future high-sensitivity radioastronomy at large in its classical range, from decametric to submillimetric wavelengths (not VLF which would require a site farther away behind the Moon).

Our strategy is different from the one of a recent International Telecommunication Union Recommendation (ITU 1997). Instead of asking for protection of selected radio frequency bands on nearly all of the farside of the Moon, we ask for protection of all frequencies at a selected modest farside locale. We think this approach would have a better chance to lead to a real understanding between scientific and commercial antagonistic interests. Radioastronomers really do not need such a vast expanse as the ITU shielded farside zone. On the other hand they need all of the frequencies because of the numerous unexpected new interesting frequencies they (most happily) keep discovering along their investigations, or simply because of large redshifts due to the natural expansion of the Universe.

It is possible that both of these two different strategies might be used jointly to obtain more advantageous bargains. 
Note that for the next 20-30 years we need protection from radio emissions created up to the geostationary orbits where the bulk of powerful industrial/commercial-scale PFI will originate. The farther away satellites/probes, more in the scientific realm, could be taken care of by bodies such as COSPAR Panel on Potentially Environmentally Detrimental Activities in Space (PEDAS).

Consequently I take opportunity of this Joint Discussion No. 22 "Astronomy from the Moon" to present a project of resolution along this new type strategy.

NO PROTECTION, NO LUNAR RADIOASTRONOMY DEPLOYMENT. NO DEPLOYMENT, NO MORE RADIO WINDOW ON THE UNIVERSE!

\section{DRAFT OF A RESOLUTION}

Concerning the protection of a potential observatory on the far side of the Moon for the future of high-sensitivity radioastronomy.

\section{Considering}

1. that radioastronomical telescopes, being ground-based or based in near-Earth space, are subjected to human-made radio frequency interference (RFI).

2. that this RFI is increasing with time, mainly from constellations of near-Earth communication satellites

3. while the radioastronomical observations are more and more sensitive, then more and more spoiled by this RFI,

\section{Deploring}

1. that even in the radioastronomy protected frequency bands, RFI spoils more and more the scientific observations,

2. that past experience and practice unfortunately demonstrate that on/near-Earth radioastronomy is doomed,

\section{Concludes}

that its survival requires a still pristine environment.

\section{Noting further}

1. that the closest practically RFI-free environment, for the time being, is the far side of the Moon, at a three-days travel time from Earth,

2. that, before being able to set there a future radioastronomical observatory, other enterprises for exploring/exploiting the Moon might very well have already spoiled this lunar farside environment,

\section{Declare}

that it is urgent to start action to protect it from RFI for the next decades, in particular for the scientific radio investigation of the Universe.

\section{Realizing however}

1. that radioastronomers should aim at general memorandum of understanding between parties, item then should minimize as much as possible their requirements, in contrast to a recent Recommendation from the International Telecommunication Union aimin at protecting all of the invisible farside,

\section{Recognize}

that a proposal such as the SAHA crater one is worth considering as a starting point for action,

\section{Then urge}

that the IAU EC supports the above titled resolution.

\section{REALISTIC VIEW OF THE PROPOSED RADIO OBSERVATORY SITE}

(Plate 1 - following page, from top left to bottom right, reading style)

On their way to the Moon, Apollo Astronauts saw simultaneously the near-(left) and farside (right); 
Saha (a half-radius under center) is one among a jungle of craters, East of the black Mare Smythii plain.

The trail from Mare Smythii (upper left) to Saha (lower right) is $350 \mathrm{~km}$ long; it was drawn for minimized slopes; three laser relays (tick marks) at strategic locations would provide telepresence and data flows with Earth.

Apollo rovers already drove tens of $\mathrm{km}$ with two passengers on board along the friendly regolith. Though the background mountain $3 \mathrm{~km}$ away is already $2,000 \mathrm{~m}$ high, the landscape is soft.

In 1966 a robotic Lunar Orbiter overflew the West part of Saha; its $100 \mathrm{~km}$ diameter floor harbors various useful topographic features and is circled by a stron $3,000 \mathrm{~m}$ high wall (here North is to the right).

The similar, but farther away, Thompson crater being overflown by an Apollo; the strong rim would protect the vast floor from lunar ground-based RFI. In the arena very extensive radioastronomical paraphernalia could be deployed.

Saha is not far away! Here, an Apollo LEM, after a three day flight, passes above Saha and darts along the Moon equator toward the grey Mare Smythii, inundated by the earthly radio frequency interference (NASA \& Heidmann documents).

\section{References}

Gérard, E., 1993, "La radioastronomie face á la saturation du domaine hertzien", La viedes sciences, Montmerle ed., C. R. Ac. Sc., 10, \#3, 175 .

Gérard, E., 1997, "Sombre perspective poru la radioastronomie du XXIéme siécle: que faire?", J. Astr. Fr. 52, 40.

Heidmann, J. 1997a, "A call for SETI well into the 21st century", Astronomical and biochemical origins and the search for life in the Universe, Cosmovici, Bowyer and Werthimer eds., 5th Intern. Conf. on Bioastronomy and IAU Coll. No. 161, 777.

Heidmann, J. 1997b, "Recent progress on the lunar farside crater Saha proposal: Toward a dedicated lunar radio observatory", International Astronautical Federation 48th Congress, Torion, paper IA A-97-IAA.9.1.05, Paris IAF Office.

ITU, 1997, "Protection of frequencies for radioastronomical measurements in the shielded zone of the Moon". International Telecommunications union, Study Group 7, radiocommunication Assembly, Geneva, ITU-RRA.479-4.

McNally, D., 1992, "Introduction - The effect of civilization on observational astronomy", The vanishing Universe: Adverse environmentsl impacts on astronomy, McNally ed., Cambridge Un. Press, 3.

Roth, J., 1997, "Will the Sun set on radioastronomy?", Sky \& Telesc., April, 40.

Whiteoak, J. B., 1993, "The threat to radioastronomy", The vanishing Universe: Adverse environmentsl impacts on astronomy, McNally ed., Cambridge Un. Press, 75.

Whiteoak, J. B., 1997, Reports on Astronomy, XXIIIA, "Progress and developements of radioastronomy", draft. 
